\title{
Effects on Quality Properties of Pork Sausages Enriched with Sea Buckthorn (Hippophae rhamnoides L.)
}

\author{
Anna Marietta Salejda, ${ }^{1}$ Agnieszka Nawirska-Olszańska, ${ }^{2}$ \\ Urszula Janiewicz, ${ }^{1}$ and Grażyna Krasnowska ${ }^{1}$ \\ ${ }^{1}$ Department of Animal Products Technology and Quality Management, Wrocław University of Environmental and Life Sciences, \\ 37 Chetmońskiego Str., 51-630 Wroclaw, Poland \\ ${ }^{2}$ Department of Fruit, Vegetable and Nutraceutical Technology, Wrockaw University of Environmental and Life Sciences, \\ 37 Chetmońskiego Str., 51-630 Wroclaw, Poland
}

Correspondence should be addressed to Anna Marietta Salejda; anna.salejda@upwr.edu.pl

Received 18 April 2017; Accepted 27 June 2017; Published 1 August 2017

Academic Editor: Giuseppe Zeppa

Copyright (C) 2017 Anna Marietta Salejda et al. This is an open access article distributed under the Creative Commons Attribution License, which permits unrestricted use, distribution, and reproduction in any medium, provided the original work is properly cited.

\begin{abstract}
The present study was aimed at evaluating the effect of a sea buckthorn (Hippophae rhamnoides L.) fruit extract on selected quality properties of cooked sausages. The ethanolic extract of sea buckthorn fruit (SBE) incorporated at the highest level (3\%) significantly affected the $\mathrm{pH}$, weight losses, and instrumental color parameters of sausages. The SBE deteriorated organoleptic properties of sausages like juiciness, overall appearance, texture, and taste; however the sausages manufactured with 1.5\% SBE were scored higher for color and almost the same as control for smell acceptance. Textural parameters like hardness, springiness, gumminess, and chewiness of cooked sausages decreased along with SBE addition. After 28 days of storage, the samples with $1.5 \%$ SBE addition were as springy, hard, and gummy as the control ones. Incorporation of SBE increased the shelf life of sausages. The highest inhibition of lipid oxidation was observed in the samples manufactured with $1.5 \%$ SBE. The SBE significantly improved the microbial qualities of sausages.
\end{abstract}

\section{Introduction}

The increased interest of consumers as to the nature and composition of the purchased foods as well as an increase of nutritional awareness make the consumer want to buy and consume foods safe for health, produced with natural ingredients, without artificial additives, and processed as little as possible. The desire to meet consumer expectations meant that the producers began to look for new, natural food additives, for example, plant-derived substances. Raw materials of plant origin, that is, leaves, flowers, fruit, seeds, or bark, are readily available sources of natural substances which may exhibit antioxidant and/or antimicrobial properties and, by this mean, raise the quality and sustainability of food products [1-4]. Plant preparations are more accepted by consumers because of natural origin, as well as the potential, beneficial effects on human health. Their use in food production is a major challenge for manufacturers but may bring tangible results [5-9].

The amount of valuable phytochemicals in plant preparations depends on the applied techniques and solvents in the extraction process [10]. Properly chosen extraction technique must guarantee that potential bioactive substances are not lost, chemically modified, or destroyed [11]. Reagents used for extraction should be selected accordingly to the solubility of plant compounds. For example, polar solvents (e.g., acetone, acetonitrile, propanol, and ethanol) are commonly used for the extraction of hydrophilic compounds such as flavonols, polyphenols, or tannins [10].

Sea buckthorn (Hippophae rhamnoides L.) fruit exhibit health enhancing properties on human body due to the wealth of biologically active substances, which include 
flavonoids, carotenoids, vitamins, and valuable minerals. The rich chemical composition and numerous health-related advantages make sea buckthorn applicable for medicinal purposes in Chinese medicine since the Tang Dynasty [12]. Healing properties have been ascribed not only to sea buckthorn fruits, but also to the leaves and bark of the bush. Sea buckthorn is used in the treatment of gastrointestinal diseases, inflammation of the lungs and joints, skin disorders, asthma, and hypertension. Oil of sea buckthorn fruit raises the efficiency of the immune system, has an antiatherogenic potential, and delays the ageing processes of the body. It also shows strong antibacterial properties and is used in the fight against many diseases of the digestive system. Infusions of the leaves and twigs bring relief from diarrhea diseases, whereas infusions of seeds relieve constipation [13-15]. Juices and syrups are complementary dietary sources of vitamins and nutrients and are recommended for the treatment of gastrointestinal diseases and avitaminosis. They have also a beneficial effect on the digestive processes. The unique chemical composition of sea buckthorn makes the usability of this plant extremely broad, in both the cosmetics and pharmaceutical industry. Fruit of this shrub are widely used in food processing, that is, for the production of jellies, juices, jams, preserves, fruit liqueurs, and wines [14, 16, 17]. The seed and pulp oils are used in oil-incorporated daily foodstuffs, such as bread, juice, and yoghurts [18]. Residues from juice and oil extraction from sea buckthorn, such as leaves, fruit, pulp, and seed, still contain valuable chemical substances at low concentrations and could be incorporated into a value-added product [19]. Results of our own studies [20] indicate that water infusion from dried sea buckthorn berries improves the texture of pork sausages, while addition of its powder effectively prolongs the shelf life of final products. Unfortunately, the utilization of sea buckthorn in the production deteriorates the technological parameters, that is, weight losses and cooking yield. Taking into account the above results, the authors conduct further research into the possibility of using sea buckthorn in shaping the quality of meat products.

The objective of this study was, therefore, to evaluate the effect of ethanolic extract of dried sea buckthorn fruit on the quality of pork sausages. By using the collected results we aimed at assessing the feasibility of replacing some chemical additives in meat processing by ingredients of plant origin.

\section{Materials and Methods}

2.1. Ingredients. The postrigor pork cuts ( $m$. semimembranosus) and skinned backfat were obtained from the Meat Processing Plant "Edward and Grzegorz Dworeccy" (Golejewo, Poland) and delivered $48 \mathrm{~h}$ postmortem to the Department of Animal Products Technology and Quality Management, Wroclaw University of Environmental and Life Sciences. Raw materials were cleaned, cut into strips, and ground (W-82AN Spomasz, Zary, Poland; $0.3 \mathrm{~cm}$ plate diameter).

The ingredients used for the production of ready-to-eat frankfurters-type sausages are based on the recipe developed by Salejda et al. [20], with the exception of the form of added plant preparation. In presented study the ethanolic extract (SBE) of dried sea buckthorn (Hippophae rhamnoides L.) fruit (SB) was used.

2.2. Characterization of Plant Material. Dried sea buckthorn fruit (SB) were grounded to powder (Thermomix TM21, Vorwerk, France), weighing approximately $0.1 \mathrm{~kg}$ and then vacuum packaged, frozen, and stored at $-18^{\circ} \mathrm{C}$ until use.

2.2.1. Acidity. Titratable acidity of SB samples was determined by using a $\mathrm{pH}$ meter (IQ's Scientific Instruments) [21]. The samples were transferred to a volumetric flask $(100 \mathrm{ml})$ and filled with water. Prepared samples were boiled and filtered after cooling down. About $10 \mathrm{ml}$ of obtained filtrate was titrated with $\mathrm{NaOH}\left(0.1 \mathrm{~mol} \mathrm{~L}^{-1}\right)$ up to $\mathrm{pH}$ 8.1. The measurements were performed in triplicate and expressed as $\%$ malic acid.

2.2.2. Vitamin C Content. Vitamin C content was determined according to the Polish Standard PN-A-04019:1998 [22]. The SB samples were titrated with the blue dye of 2.6dichloroindophenol until reaching a pink color.

The content of ascorbic acid (AA $[\mathrm{mg} / \mathrm{L}])$ was calculated as follows:

$$
\mathrm{AA}[\mathrm{mg} / \mathrm{L}]=\frac{\left(V_{i} \times 63\right)}{V_{p}},
$$

where $V_{i}$ is volume of 2,6-dichlorophenolindophenol and $V_{p}$ is volume of the sample.

2.2.3. Total Carotenoids Contents. The content of carotenoids was calorimetrically determined using the method of Wrolstad et al. [23]. Approximately $2 \mathrm{~g}$ of SB powder was stirred slightly with $15 \mathrm{~mL}$ of $100 \%$ acetone and then left at $4^{\circ} \mathrm{C}$. After $24 \mathrm{~h}$ the extract was centrifuged at $12.500 \mathrm{rpm}$ for $5 \mathrm{~min}$, and the supernatants were recovered. Absorbance was taken at $470 \mathrm{~nm}$ (Shimadzu UV-160A spectrophotometer). The total carotenoids ( $\mathrm{Ca}$ ) were calculated using the following formulae: $\mathrm{Ca}=1000 * A_{470}-\left(1.9 \mathrm{Ch}_{\mathrm{a}}+63.14 \mathrm{Ch}_{\mathrm{b}}\right) / 214$, where $A$ is absorbancy at corresponding wavelengths; the values 1.9 and 63.14 are molar absorptivity coefficients for acetone (absorption of $1 \mathrm{~cm}$ ).

2.2.4. Total Polyphenols, ABTS, and FRAP Assay. Samples for the analysis of polyphenols, ABTS, and FRAP were prepared as follows. Approximately $0,5 \mathrm{~g}$ of sea buckthorn fruit powder was weighed into a test tube for antioxidant property analysis. A total of $7-10 \mathrm{~mL}$ of $80 \%$ aqueous ethanol was added, and the suspension was stirred slightly. The samples were sonicated for $15 \mathrm{~min}$ and left at $4^{\circ} \mathrm{C}$. After $24 \mathrm{~h}$ the extract was centrifuged at $12.500 \mathrm{rpm}$ for $5 \mathrm{~min}$, and the supernatants were recovered.

Total polyphenols were determined by the FolinCiocalteu method [24] using gallic acid (GA) as a standard for the calibration curve. After $1 \mathrm{~h}$ the results were read at $765 \mathrm{~nm}$ in a spectrophotometer (Shimadzu UV-2401 PC). All determinations were performed in triplicate. The results of 
the assay were calculated and expressed as milligrams of GA equivalent (GAE) per 100 grams of dry weight (DW).

The $\mathrm{ABTS}^{+}$radical scavenging activity was measured according to the method developed by Re et al. [25]. The $\mathrm{ABTS}^{+}$solution was diluted with redistilled water until the absorbance of $0.700(0.02)$ at $743 \mathrm{~nm}$ was achieved. Upon addition of $60 \mu \mathrm{L}$ of the supernatant to $3 \mathrm{~mL}$ of diluted $\mathrm{ABTS}^{+}$solution, absorbance was read (spectrophotometer Shimadzu UV-2401 PC) exactly 6 min after initial mixing. All determinations were performed in triplicate.

The ferric reducing potential was determined using the FRAP assay proposed by Benzie and Strain [26]. The supernatant $(0.30 \mathrm{~mL})$ and FRAP reagent $(3 \mathrm{~mL})$ were added to each well and mixed thoroughly. Absorbance was taken at $593 \mathrm{~nm}$ after $10 \mathrm{~min}$. All determinations were performed in triplicate.

A standard curve for ABTS and FRAP assay was prepared using different concentrations of Trolox. Trolox equivalent antioxidant capacity (TEAC) values were calculated and are expressed as Trolox equivalents (TE) per 100 gram of dry weight (DW).

2.2.5. Analysis of Organic Acids. Organic acids were determined by HPLC method, isocratically, using $0.001 \mathrm{~N}$ sulphuric acid, at wavelength $210 \mathrm{~nm}$ and flow $0.6 \mathrm{ml} \cdot \mathrm{min}^{-1}$ [27]. Assessment was done with the use of liquid chromatograph produced by Dionex (USA), equipped with LED model detector Ultimate 3000. The latter one cooperated with the following devices: LPG-3400A pomp, autosampler EWPS3000SI, column thermostat TCC-3000SD, and computer software Chromeleon v.6.8. Separation was conducted on Aminex HPH-87 H $(300 \times 7.8 \mathrm{~mm})$ column with IG Cation $\mathrm{H}(30 \times 4.6)$ precolumn by Bio-Red firm, at the temperature of $65^{\circ} \mathrm{C}$.

2.3. Preparation of SBE. Ethanolic extract (SBE) of dried sea buckthorn (Hippophae rhamnoides L.) fruit was prepared according to method by Jia et al. [28] with slight modification. Consequently, $10 \mathrm{~g}$ of dried fruit was mixed with $100 \mathrm{~mL}$ of $40 \%$ ethanol at room temperature for $12 \mathrm{~h}$ in an enclosed flask with constant agitation followed by filtering through Whatman number 2 filter paper. Filtrates were subsequently concentrated on a rotary vacuum evaporator BÜCHI R215 (BÜCHI Labortechnik GmbH, Deutschland) at $40^{\circ} \mathrm{C}$, $120 \mathrm{rpm}$, and $100 \mathrm{mbar}$. The semidried samples were then reconstituted in a final volume of $5 \mathrm{~mL}$ of distilled water.

2.4. Preparation of Experimental Products. Three different meat emulsions were prepared (Table 1): Treatment C: control samples without SBE addition; Treatments 1 and 2: samples supplemented, respectively, with $1.5 \mathrm{~g}$ and $3.0 \mathrm{~g}$ of SBE. The production process of experimental products was similar to that conducted by Salejda et al. [29]. Briefly, raw materials together with all ingredients were homogenized, packed in polypropylene tubes, and thermally treated to $72^{\circ} \mathrm{C}$ in the center of batters. Next, experimental products were cooled down to $21^{\circ} \mathrm{C}$ and then vacuum-packed and stored for 4 weeks at $4 \pm 1^{\circ} \mathrm{C}$. The experiment was replicated in two independent
TABLE 1: Formulation (g) of meat batters.

\begin{tabular}{lcccccc}
\hline Treatments & Pork & Backfat & CS & SI & Ice & SBE \\
\hline C & 70 & 30 & 1.5 & 0.07 & 25 & 0 \\
1 & 70 & 30 & 1.5 & 0.07 & 25 & 1.5 \\
2 & 70 & 30 & 1.5 & 0.07 & 25 & 3 \\
\hline
\end{tabular}

CS: curing salt, SI: sodium isoascorbate, and SBE: sea buckthorn fruit extract.

production series. All analyses were conducted immediately after the production process on cooled down meat products and on products after 28 days of storage at $4 \pm 1^{\circ} \mathrm{C}$.

\subsection{Characterization of Experimental Products}

2.5.1. $\mathrm{pH}$ Measurement. The $\mathrm{pH}$ value was measured directly in products with a $\mathrm{pH}$ meter electrode (Orion 3-Star $\mathrm{pH}$ Benchtop Meter, Thermo Fisher Scientific Inc.) at room temperature.

2.5.2. Weight Losses and Yield of Cooking Process. Weight losses were determined in the samples as cooking losses directly after the production process. Weight losses were expressed as a percentage of initial sample weight. The yield of the cooking process was calculated from the following equation:

$$
\begin{aligned}
\% \text { Cooking yield }= & \frac{\text { weight after heat treatment }}{\text { weight of raw materials }} \\
& \times 100 .
\end{aligned}
$$

2.5.3. Sensory Evaluation. The sensory properties (overall appearance, smell, color, taste, texture, and juiciness) of model final products were determined according to the Polish Standard PN-ISO 4121:1998 [30]. The experimental products directly after the production process were cut into $1 \mathrm{~cm}$ slices, encoded, and served. Evaluation was performed at room temperature $\left(22 \pm 1^{\circ} \mathrm{C}\right)$, under white light by ten previously trained panelists using a nine-point hedonic rating scale of acceptance (scale from 1, like extremely, to 9, dislike extremely, Lewless and Hildegarde [31]).

2.5.4. Texture Profile Analysis. The TPA 70 test (75\% deformation, head speed $60 \mathrm{~mm} / \mathrm{min}$, and relaxation time $30 \mathrm{~s}$ ) was applied for the texture profile analysis of model meat products. The Zwick/Roell Z010 testing machine (Zwick Testing Machines Ltd., Leominster Herefordshire, UK) was used. Samples of sausages were cut into slices $(15 \times 25 \mathrm{~mm})$ before each measurement. The following textural parameters were measured: cohesiveness, springiness, hardness, gumminess, and chewiness. The measurements were conducted at room temperature $\left(22 \pm 1^{\circ} \mathrm{C}\right)$, directly after the production process (Day 0 ) and after 4 weeks (Day 28) of storage.

2.5.5. Color Measurement. The color of the cooked sausages surface (slices, $15 \times 25 \mathrm{~mm}$ ) was expressed by $L^{*}$ (lightness), $a^{*}$ (redness), and $b^{*}$ (yellowness) parameters in the CIE 
Lab system (reflectance colorimeter Minolta CR-400). The analysis was carried out at room temperature $\left(22 \pm 1^{\circ} \mathrm{C}\right)$, directly after production (Day 0) and after 4 weeks (Day 28) of chill storage.

2.5.6. Lipid Oxidation (TBARS Test). The effect of SBE on lipid oxidation of the sausages (initially and after 28 days of storage) was evaluated using a spectrophotometric 2thiobarbituric acid (TBA) filtration method described by Luciano et al. [32] with slight modifications. Briefly, $0.5 \mathrm{~g}$ of ground sample was homogenized with $10 \mathrm{~mL}$ of $10 \%$ trichloroacetic acid (Chempur, Piekary Slaskie, Poland) and centrifuged (Sigma 3K30; Sigma Laborzentrifugen $\mathrm{GmbH}$, Osterode am Harz, Germany) at room temperature and $4000 \mathrm{rpm}$ for $10 \mathrm{~min}$. Homogenates were filtered through Whatman number 1 filter paper. Then, $2 \mathrm{~mL}$ of clear filtrate was mixed with $2 \mathrm{~mL}$ of $0.02 \mathrm{M}$ aqueous thiobarbituric acid (Sigma-Aldrich, St. Louis, MO, USA), and the samples were incubated in a water bath at $100^{\circ} \mathrm{C}$ for $40 \mathrm{~min}$ (Julabo TW12, Julabo Inc., Allentown, USA). The absorbance of supernatant was measured at $532 \mathrm{~nm}$ (spectrophotometer Rayleigh UV-1800, Beijing Rayleigh Analytical Instrument Corp., China). The TBARS values were expressed as mg of malondialdehyde (MDA) per kg of sample calculated using 1,1,3,3-tetraethoxypropane (Sigma-Aldrich) as the standard. The determination was conducted immediately after the production process (Day 0) and after 2 and 4 weeks (Day 14, 28) of storage.

2.6. Antimicrobial Assay. The antimicrobial effect of used plant preparation was measured according to the pour plate method described by Salejda et al. [29]. The results of antimicrobial assay were expressed as the total count of microorganisms in $1 \mathrm{~g}$ of sample. All analyses were repeated in samples of experimental products after 28 days of storage at $4 \pm 1^{\circ} \mathrm{C}$.

2.7. Statistical Analysis. To find the effects between treatments the data were analyzed using Duncan's multiple range test $(P \leq 0.05)$ (Statistica software ver. 8.0., StatSoft Inc., Krakow, Poland). The results were presented as mean values and standard error (mean \pm standard error).

\section{Results and Discussion}

The addition of SBE significantly $(P \leq 0.05)$ influenced the $\mathrm{pH}$ values of sausages. The acidity of final products was increasing along with a growing content of the plant additive in the recipe $(P \leq 0.05)$. The sausages manufactured with $3 \%$ of ethanolic extract of sea buckthorn fruit had the lowest $\mathrm{pH}$, while the samples manufactured without SBE addition had the highest $\mathrm{pH}(4.69,5.89$, resp.). Similar results were observed by Salejda et al. [20] on pork sausages manufactured with powder and water infusion of dried sea buckthorn fruit.

The decreasing $\mathrm{pH}$ value was accompanied by increasing weight losses measured after production process, that is, from $5.61 \mathrm{~g} / 100 \mathrm{~g}$ in control samples to $16.8 \mathrm{~g} / 100 \mathrm{~g}$ in sausages with the highest SBE addition. The same tendency was observed for results of cooking yield. The increase of weight losses

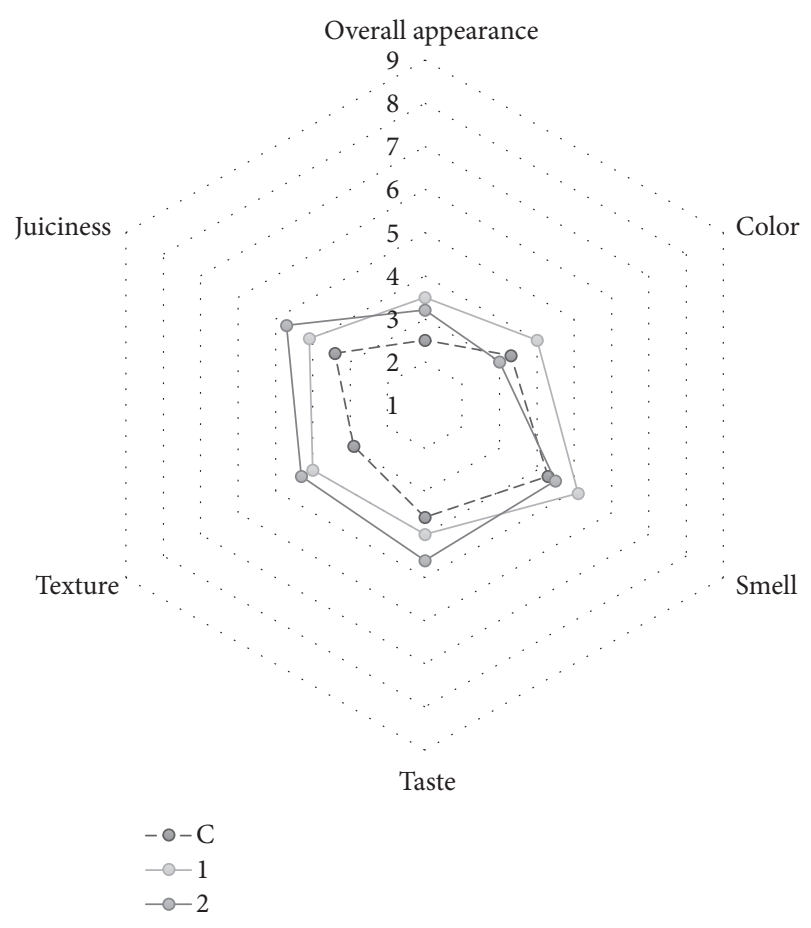

FIGURE 1: Sensory evaluation of meat products.

might be related to low $\mathrm{pH}$ values of batters, which decreases the ability of experimental emulsions to bind water and fat after protein denaturation [33,34]. High acidity of experimental batters might be caused by addition of plant material, which was characterized by titratable acidity at $23.69 \% \pm$ 0.98 malic acid and high vitamin $\mathrm{C}$ and malic acid content (1895 mg/100 g DW and $948 \mathrm{mg} / 100 \mathrm{~g}$ DW, resp.). Previous studies conducted by Salejda et al. [20] also confirmed the negative effects of sea buckthorn fruit preparations on weight losses and thereby on the yield of pork sausages production process.

The sausages manufactured with SBE addition were scored lower by panelists in the case of juiciness, overall appearance, texture, and taste than the control samples (Figure 1). Lower acceptability of juiciness might be related to high weight losses during the cooking of meat products manufactured with the SBE. However, the samples with the addition of the plant extract at the lowest level were scored higher in the case of color and almost the same as control samples in the case of smell assessment. In studies on antioxidant properties of sea buckthorn berry residues, Püssa et al. [35] demonstrated that $2 \%$ supplement of berry powder did not deteriorate the organoleptic properties like taste, flavor, or texture of the patties prepared from mechanically deboned meat of chicken and turkey.

An important role in determining textural properties of cooked frankfurters is ascribed to the good quality of gel matrix [36]. Table 2 presents the effect of adding SBE, at different doses, on the textural properties of cooked pork sausages directly after the production process and after 28 days of chill storage. Texture profile analysis (TPA) demonstrated a significant reduction $(P \leq 0.05)$ in all the textural 
TABLE 2: Results of TPA test directly after production process (0 days of storage) and after 28 days of chill storage.

\begin{tabular}{lcccccc}
\hline Treatment & Days & Cohesiveness [-] & Springiness [mm] & Hardness [N] & Gumminess [Nm] & Chewiness [N] \\
\hline C & 0 & $7.32 \pm 0.38^{\mathrm{a}}$ & $0.82 \pm 0.05^{\mathrm{b}}$ & $31.5 \pm 2.47^{\mathrm{C}}$ & $17.1 \pm 1.7^{\mathrm{C}}$ & $14.3 \pm 1.16^{\mathrm{c}}$ \\
& 28 & $7.49 \pm 0.23^{\mathrm{A}}$ & $0.85 \pm 0.07^{\mathrm{A}}$ & $39.6 \pm 2.20^{\mathrm{B}}$ & $19.8 \pm 2.63^{\mathrm{B}}$ & $17.4 \pm 1.33^{\mathrm{C}}$ \\
1 & 0 & $7.35 \pm 0.22^{\mathrm{a}}$ & $0.73 \pm 0.08^{\mathrm{a}}$ & $25.6 \pm 2.49^{\mathrm{b}}$ & $9.44 \pm 1.09^{\mathrm{b}}$ & $4.3 \pm 1.06^{\mathrm{b}}$ \\
& 28 & $7.49 \pm 0.25^{\mathrm{A}}$ & $0.79 \pm 0.04^{\mathrm{A}}$ & $39.4 \pm 3.40^{\mathrm{B}}$ & $17.3 \pm 1.37^{\mathrm{B}}$ & $14.1 \pm 1.15^{\mathrm{B}}$ \\
2 & 0 & $7.45 \pm 0.18^{\mathrm{a}}$ & $0.73 \pm 0.06^{\mathrm{a}}$ & $14.8 \pm 1.92^{\mathrm{a}}$ & $4.99 \pm 0.98^{\mathrm{a}}$ & $2.87 \pm 0.32^{\mathrm{a}}$ \\
& 28 & $7.64 \pm 0.29^{\mathrm{A}}$ & $0.82 \pm 0.07^{\mathrm{A}}$ & $26.7 \pm 3.51^{\mathrm{A}}$ & $9.67 \pm 0.85^{\mathrm{A}}$ & $8.34 \pm 0.95^{\mathrm{A}}$ \\
\hline
\end{tabular}

$\overline{\mathrm{ABC} / \mathrm{abc}}$ Different letters indicate significant differences $(P \leq 0.05)$ between values, $n=5$.

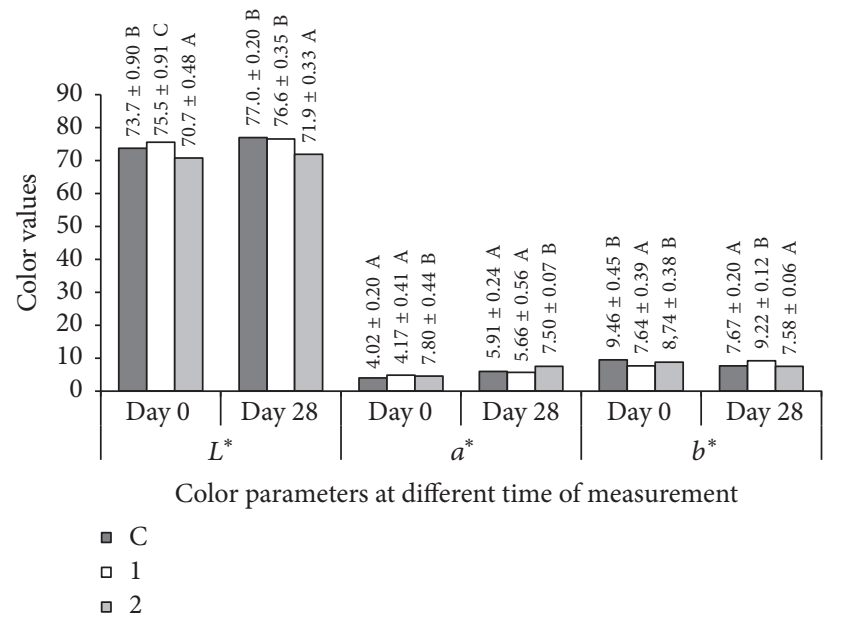

FIGURE 2: CIE $L^{*}, a^{*}$, and $b^{*}$ indicate values of meat products; ${ }^{\mathrm{ABC}}$ different letters indicate significant differences $(P \leq 0.05)$ between values.

parameters of the pork sausages measured after cooking, except cohesiveness, which was statistically the same for all formulations. The higher values of hardness of the control formulations might be related to the higher $\mathrm{pH}$ of batters and better fat and water retention [37]. SBE addition increased the acidity of meat batters and probably reduced the binding ability of meat particles [38]. High weight losses caused by lower $\mathrm{pH}$ of meat batters could also reduce the elasticity and springiness of the sausages, which was observed in the samples manufactured with SBE. After 28 days of chill storage, the samples with $1.5 \%$ SBE addition were as springy, hard, and gummy as the control samples. A similar effect was reported by Tril et al. [39] in studies on meat products prepared with chokeberry juice. The increased content of a plant additive in the recipe caused a decrease of texture parameters directly after the cooking process. While, during the chill storage, values of the measured parameters were observed to increase. The increase of hardness during chill storage of food emulsions might be related to the process of emulsion destabilization due to water and fat separation from the protein matrix [40].

SBE addition significantly affected $(P \leq 0.05)$ the color parameters of sausages expressed by $L^{*}, a^{*}$, and $b^{*}$ parameters in the CIE Lab system (Figure 2). The application of $3 \%$ of $\mathrm{SBE}$ to the recipe of sausages caused a significant

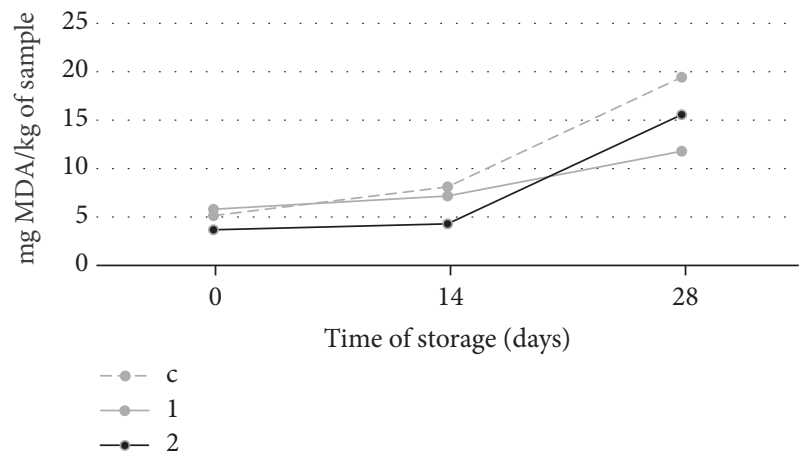

FIGURE 3: TBA values of meat products.

$(P \leq 0.05)$ reduction of lightness $\left(L^{*}\right)$ and increase of redness $\left(a^{*}\right)$. This effect was also observed in the samples after 28 days of chill storage. Darkening of model meat products manufacturing with addition of sea buckthorn fruit preparations (powder and water infusion) was observed also by Salejda et al. [20]. The same result of the applied plant additive was also observed by Yu et al. [41] in cooked poultry meat produced with a water extract of rosemary. FernándezLópez et al. [40] also confirmed these results in beef meatballs with the addition of rosemary, garlic, orange, and lemon extracts. The authors attributed higher intensity of red color of experimental sausages to the high content of carotenoids $(89.11 \mathrm{mg} \pm 2.26 / 100 \mathrm{~g}$ DW) measured in used plant additive. The contribution of yellow color $\left(b^{*}\right)$ in the whole spectra of the experimental cooked pork sausages was the same in the samples manufactured with the highest level of SBE addition as in the control samples immediately after the production process as well as after storage (8.74 and 9.46, 7.58, and 7.67, resp.). The statistically significant changes in color parameters of cooked sausages were confirmed by results of sensory evaluation (Figure 1). The samples with 1.5\% SBE addition were scored higher than the sausages manufactured without plant additive, although the increase of SBE in the recipe caused a decrease of color acceptance by the panelists.

The effect of SBE on lipid oxidation expressed by TBARS values in cooked pork sausages during storage at $4^{\circ} \mathrm{C}$ for 14 and 28 days is shown in Figure 3. The applied plant additive significantly $(P \leq 0.05)$ influenced the TBARS values. For the first 14 days of chill storage, the lowest TBARS values were obtained for the samples with the $3 \%$ addition of SBE and the highest ones for the samples produced without 
plant additive. However, after 28 days of storage, the highest inhibition of lipid oxidation was observed in the samples manufactured with $1.5 \%$ SBE. Over the storage period, also the $\triangle$ TBARS was the lowest in the case of Treatment 1 and the highest in the case of Treatment C (6.02 mg MDA $/ \mathrm{kg}$ of sample and $14.32 \mathrm{mg} \mathrm{MDA} / \mathrm{kg}$ of sample, resp.). These results were in agreement with previous studies of Salejda et al. [20] who indicated the strong antioxidant effect of dried sea buckthorn fruit on lipid peroxidation in pork sausages. Also Püssa et al. [35] or Jia et al. [28] reported that extracts of colored fruit significantly decreased the thiobarbituric acidreactive substance values in meat products. Inhibitory effect upon lipid oxidation process, observed in own study, might be related to antioxidant properties of carotenoids, vitamin $\mathrm{C}$, and polyphenols present in sea buckthorn fruit added to meat batters. The obtained results indicated that used plant additive contains $1899.76 \pm 157.4 \mathrm{mg} \mathrm{GA} / 100 \mathrm{~g}$ DW of total polyphenols, which demonstrated strong capacity to annihilation of $\mathrm{ABTS}^{\circ+}$ radicals $(17019.23 \mu \mathrm{M} \mathrm{TE} / 100 \mathrm{~g} \mathrm{DW})$ and to reduce $\mathrm{Fe}^{+3}$ ions $(9671.42 \pm 142.8 \mu \mathrm{M} \mathrm{TE} / 100 \mathrm{~g} \mathrm{DW})$.

Results of our own study showed that the addition of the SB extract was able to reduce the total microbial population of pork sausages compared to the control, during 28 days of chill storage. The study demonstrates that SBE addition at the highest level resulted in about sevenfold reduction in the total plate count in pork sausages compared to the control (2.2 $\log \mathrm{CFU} / \mathrm{g}$ and15.2 $\log \mathrm{CFU} / \mathrm{g}$, resp.). The poorer growth of spoilage microorganisms in the sausages incorporated with SBE might be due to the inhibitory effect of the plant extract compounds. Malic acid and vitamin C, found in the test plant material in large quantity, exhibit proved antifungal and bactericidal action [42]. The ability to reduce the total microbial population in the sausage during storage also strongly indicated that SBE is a promising natural preservative that might be used instead of or in combination with chemical food additives in meat processing.

\section{Conclusions}

The ethanolic extract of sea buckthorn fruit effectively inhibited lipid oxidation. Furthermore, the addition of 3\% SBE resulted in a significant reduction in total plate count in pork sausages compared to the control ( $2.2 \log \mathrm{CFU} / \mathrm{g}$ and $15.2 \log \mathrm{CFU} / \mathrm{g}$, resp.). This suggests the potential of SBE to be used in meat processing as an alternative to chemical additives and as an inexpensive source of valuable phytochemicals with functional properties. However, the incorporation of SBE into pork sausages significantly affected the $\mathrm{pH}$, weight losses, and instrumental color parameters and also decreased the acceptability of juiciness, overall appearance, texture, and taste. Therefore future research is needed to eliminate this negative effect of SBE on sausages quality characteristics.

\section{Conflicts of Interest}

The authors declare that they have no conflicts of interest.

\section{Acknowledgments}

This study was carried out with financial support of Wroclaw University of Environmental and Life Sciences, Young Scientists Research Grant no. NO 04-04-199/28. Publication supported by Wroclaw Centre of Biotechnology programme, The Leading National Research Centre (KNOW) for years 2014-2018. Collaboration of Aleksandra Markowska and Piotr Machelak in the production and sampling is acknowledged.

\section{References}

[1] C. Jo, J. H. Son, C. B. Son, and M. W. Byun, "Functional properties of raw and cooked pork patties with added irradiated, freeze-dried green tea leaf extract powder during storage at 4 -C," Meat Science, vol. 64, no. 1, pp. 13-17, 2003.

[2] S.-J. Kim, S. C. Min, H.-J. Shin et al., "Evaluation of the antioxidant activities and nutritional properties of ten edible plant extracts and their application to fresh ground beef," Meat Science, vol. 93, no. 3, pp. 715-722, 2013.

[3] K. M. Wojciak, Z. J. Dolatowski, and A. Okon, "The effect of water plant extracts addition on the oxidative stability of meat products," Acta Scientarum Polonorum Technologia Alimentaria, vol. 10, pp. 175-188, 2011.

[4] V. Velasco and P. Williams, "Improving meat quality through natural antioxidants," Chilean Journal of Agricultural Research, vol. 71, no. 2, pp. 313-322, 2011.

[5] R. Banerjee, A. K. Verma, A. K. Das, V. Rajkumar, A. A. Shewalkar, and H. P. Narkhede, "Antioxidant effects of broccoli powder extract in goat meat nuggets," Meat Science, vol. 91, no. 2, pp. 179-184, 2012.

[6] C. Eccleston, Y. Baoru, R. Tahvonen, H. Kallio, G. H. Rimbach, and A. M. Minihane, "Effects of an antioxidant-rich juice (sea buckthorn) on risk factors for coronary heart disease in humans," Journal of Nutritional Biochemistry, vol. 13, no. 6, pp. 346-354, 2002.

[7] P. Kumar, S. Kumar, M. KTripathi et al., "Flavonoids in the development of functional meat products: a review," Veterinary World, vol. 6, no. 8, pp. 573-578, 2013.

[8] A. Lucera, C. Costa, A. Conte, and M. A. del Nobile, "Food applications of natural antimicrobial compounds," Frontiers in Microbiology, vol. 3, article 287, 2012.

[9] Y. Sultanbawa, "Science against microbial pathogens: communicating current research and technological advances," in Microbiology Series, A. Mendez-Vilas, Ed., Formatex, Badajoz, Spain, 2011.

[10] C. De Monte, S. Carradori, A. Granese, G. B. Di Pierro, C. Leonardo, and C. De Nunzio, "Modern extraction techniques and their impact on the pharmacological profile of Serenoa repens extracts for the treatment of lower urinary tract symptoms," BMC Urology, vol. 14, no. 1, article 63, 2014.

[11] Y. Zuo, H. Chen, and Y. Deng, "Simultaneous determination of catechins, caffeine and gallic acids in green, oolong, black and pu-erh teas using HPLC with a photodiode array detector," Talanta, vol. 57, no. 2, pp. 307-316, 2002.

[12] G. Suryakumar and A. Gupta, "Medicinal and therapeutic potential of Sea buckthorn (Hippophae rhamnoides L.)," Journal of Ethnopharmacology, vol. 138, no. 2, pp. 268-278, 2011.

[13] E. Christaki, "Hippophae Rhamnoides L. (Sea Buckthorn): a Potential Source of Nutraceuticals," Food and Public Health, vol. 2, no. 3, pp. 69-72, 2012. 
[14] X. Gao, M. Ohlander, N. Jeppsson, L. Björk, and V. Trajkovski, "Changes in antioxidant effects and their relationship to phytonutrients in fruits of sea buckthorn (Hippophae rhamnoides L.) during maturation," Journal of Agricultural and Food Chemistry, vol. 48, no. 5, pp. 1485-1490, 2000.

[15] N. K. Upadhyay, M. S. Yogendra Kumar, and A. Gupta, "Antioxidant, cytoprotective and antibacterial effects of Sea buckthorn (Hippophae rhamnoides L.) leaves," Food and Chemical Toxicology, vol. 48, no. 12, pp. 3443-3448, 2010.

[16] L. M. Bal, V. Meda, S. N. Naik, and S. Satya, "Sea buckthorn berries: A potential source of valuable nutrients for nutraceuticals and cosmoceuticals," Food Research International, vol. 44, no. 7, pp. 1718-1727, 2011.

[17] Z. Kawecki, M. Szalkiewicz, and A. Bieniek, "The common sea buckthorn-a valuable fruit," Journal of Fruit and Ornamental Plant Research, vol. 12, pp. 183-193, 2004.

[18] B. Yang and H. Kallio, "Composition and physiological effects of sea buckthorn (Hippophaë) lipids," Trends in Food Science and Technology, vol. 13, no. 5, pp. 160-167, 2002.

[19] T. S. C. Li, Trends in New Crops and New Uses, ASHS Press, Alexandria, Va, USA.

[20] A. M. Salejda, U. Tril, and G. Krasnowska, "The effect of sea buckthorn (Hippophae rhamnoides L.) berries on some quality characteristics of cooked pork sausages," WASET: International Journal of Biological Biomolecular Agricultural Food and Biotechnological Engineering, vol. 8, no. 6, pp. 604-607, 2014.

[21] J. Kolniak-Ostek, A. Wojdyło, J. Markowski, and K. Siucińska, "1-Methylcyclopropene postharvest treatment and their effect on apple quality during long-term storage time," European Food Research and Technology, vol. 239, no. 4, pp. 603-612, 2014.

[22] PN-A-04019:1998, "Fruit and vegetable products. Preparation of samples and test methods. Determination of vitamin C," Polish Committee for Standardization, Warszawa, 1998.

[23] R. E. Wrolstad, T. E. Acree, E. A. Decker et al., Handbook of Food Analytical Chemistry. Pigments, Colorants, Flavors, Texture, and Bioactive Food Components, John Wiley \& Sons, Inc, New York, NY, USA, 2005.

[24] K. Slinkart and V. L. Singleton, "Total phenol analysis: automation and comparison with manual method," American Journal of Enology and Viticulture, vol. 28, pp. 49-55, 1977.

[25] R. Re, N. Pellegrini, A. Proteggente, A. Pannala, M. Yang, and C. Rice-Evans, "Antioxidant activity applying an improved ABTS radical cation decolorization assay," Free Radical Biology \& Medicine, vol. 26, no. 9-10, pp. 1231-1237, 1999.

[26] I. F. F. Benzie and J. J. Strain, "The ferric reducing ability of plasma (FRAP) as a measure of 'antioxidant power': the FRAP assay," Analytical Biochemistry, vol. 239, no. 1, pp. 70-76, 1996.

[27] K. Sturm, D. Koron, and F. Stampar, "The composition of fruit of different strawberry varieties depending on maturity stage," Food Chemistry, vol. 83, no. 3, pp. 417-422, 2003.

[28] N. Jia, B. Kong, Q. Liu, X. Diao, and X. Xia, "Antioxidant activity of black currant (Ribes nigrum L.) extract and its inhibitory effect on lipid and protein oxidation of pork patties during chilled storage," Meat Science, vol. 91, no. 4, pp. 533-539, 2012.

[29] A. M. Salejda, U. Janiewicz, M. Korzeniowska, J. Kolniak-Ostek, and G. Krasnowska, "Effect of walnut green husk addition on some quality properties of cooked sausages," LWT - Food Science and Technology, vol. 65, pp. 751-757, 2016.

[30] PN-ISO 4121:1998, "Sensory analysis-Methodology-Evaluation of food products by method using scales," Polish Committee for Standardization, Warszawa, 1998.
[31] H. T. Lewless and H. Hildegarde, Sensory Evaluation of Food. Principles and Practices, Springer, New York, NY, USA, 2nd edition, 2010.

[32] G. Luciano, A. P. Moloney, A. Priolo et al., "Vitamin E and polyunsaturated fatty acids in bovine muscle and the oxidative stability of beef from cattle receiving grass or concentrate-based rations," Journal of Animal Science, vol. 89, no. 11, pp. 3759-3768, 2011.

[33] E. Chiavaro, M. Rinaldi, E. Vittadini, and D. Barbanti, "Cooking of pork Longissimus dorsi at different temperature and relative humidity values: Effects on selected physico-chemical properties," Journal of Food Engineering, vol. 93, no. 2, pp. 158-165, 2009.

[34] J. E. Hayes, V. Stepanyan, P. Allen, M. N. O'Grady, and J. P. Kerry, "Evaluation of the effects of selected plant-derived nutraceuticals on the quality and shelf-life stability of raw and cooked pork sausages," LWT - Food Science and Technology, vol. 44, no. 1, pp. 164-172, 2011.

[35] T. Püssa, R. Pällin, P. Raudsepp, R. Soidla, and M. Rei, “Inhibition of lipid oxidation and dynamics of polyphenol content in mechanically deboned meat supplemented with sea buckthorn (Hippophae rhamnoides) berry residues," Food Chemistry, vol. 107, no. 2, pp. 714-721, 2008.

[36] J. Feng and Y. L. Xiong, "Interactions and functionality of mixed myofibrillar and enzyme-hydrolyzed soy proteins," Food Science, vol. 67, pp. 2851-2856, 2002.

[37] R. Thomas, N. Jebin, K. Barman, and A. Das, "Quality and shelf life evaluation of pork nuggets incorporated with fermented bamboo shoot (Bambusa polymorpha) mince," Meat Science, vol. 96, no. 3, pp. 1210-1218, 2014.

[38] S. Cofrades, J. Ayo, A. Serrano, J. Carballo, and F. JiménezColmenero, "Walnut, microbial transglutaminase and chilling storage time effects on salt-free beef batter characteristics," European Food Research and Technology, vol. 222, no. 3-4, pp. 458-466, 2006.

[39] U. Tril, A. M. Salejda, and G. Krasnowska, "Attempt to increase oxidative stability of model meat products by applying chokeberry juice," Zywn-Nauk Technol Ja, vol. 6, no. 79, pp. 55-66, 2011.

[40] J. Fernández-López, N. Zhi, L. Aleson-Carbonell, J. A. PérezAlvarez, and V. Kuri, "Antioxidant and antibacterial activities of natural extracts: Application in beef meatballs," Meat Science, vol. 69, no. 3, pp. 371-380, 2005.

[41] L. Yu, L. Scanlin, J. Wilson, and G. Schmidt, "Rosemary extracts as inhibitors of lipid oxidation and color change in cooked turkey products during refrigerated storage," Journal of Food Science, vol. 67, no. 2, pp. 582-585, 2002.

[42] C. A. Simpson and J. N. Sofos, Ingredients in Meat Products. Properties, Functionality and Applications, Springer Science + Business Media LLC, New York, NY, USA. 

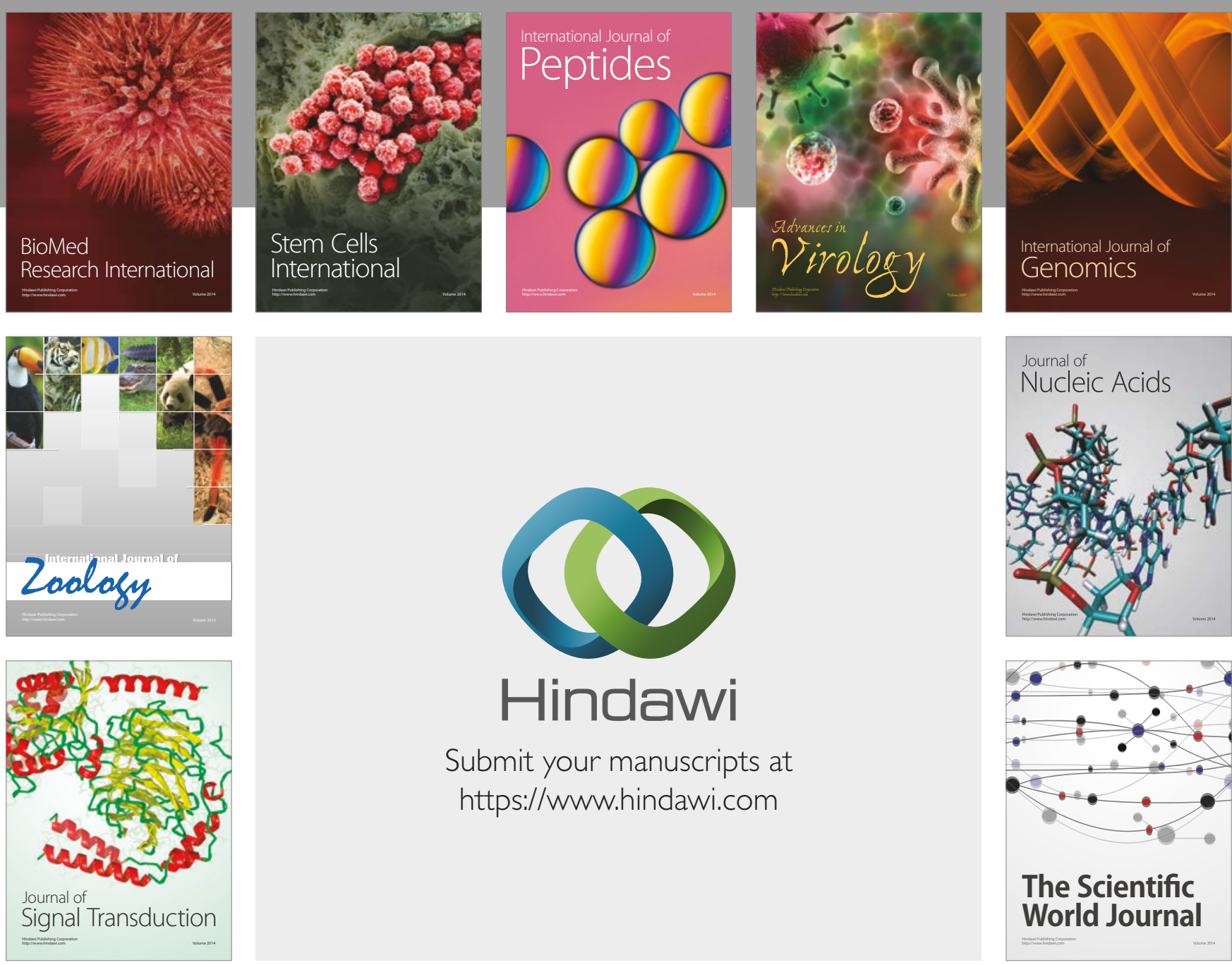

Submit your manuscripts at

https://www.hindawi.com
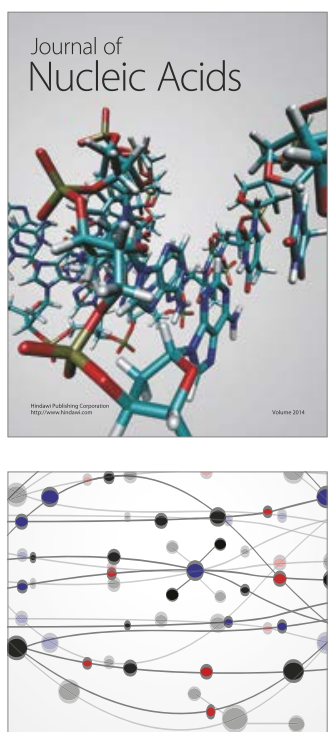

The Scientific World Journal

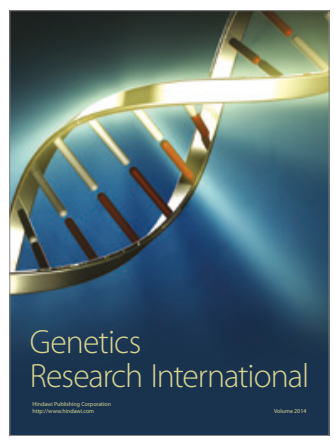

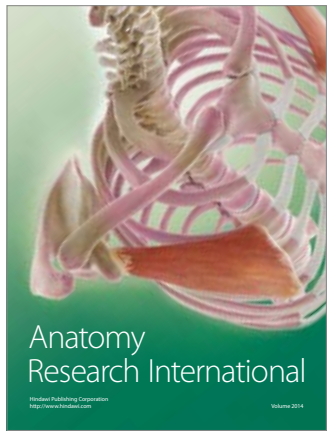

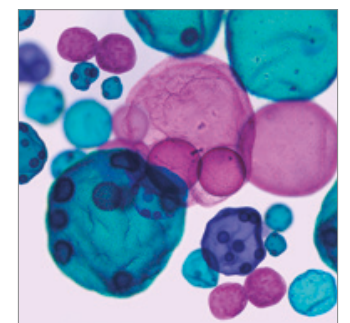

International Journal of Microbiology
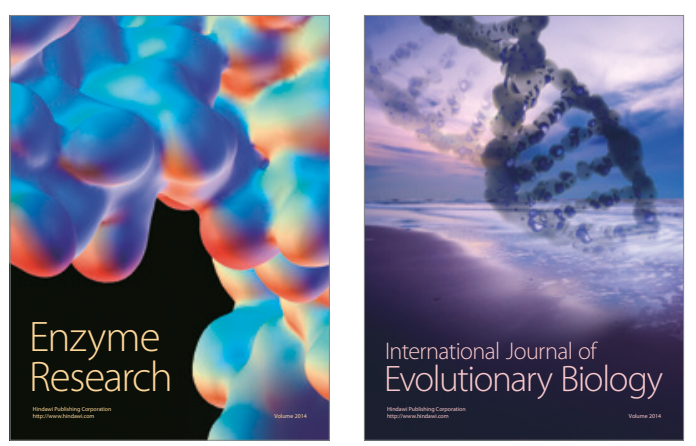
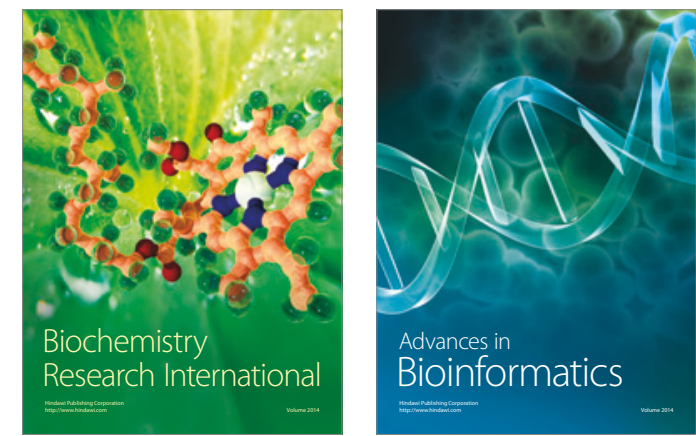

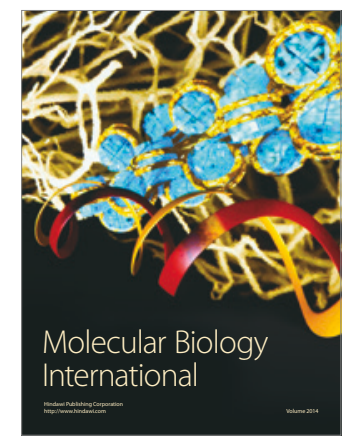

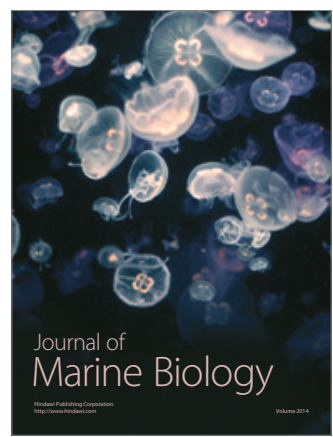

